\title{
Two-Tiered Measurement Systems in Modernizing Plants
}

\author{
JOHN E. ETTLIE
}

School of Business Administration, The University of Michigan, Ann Arbor, Michigan 48109-1234

\begin{abstract}
In this study we predicted and found evidence to support two general themes about new production systems measurement. First, there are two tiers of measures that are becoming popular to gauge performance. These two tiers are relatively independent-system-level measures like uptime, and business-level outcomes like return on investment. Second, when measures from these two categories are significantly correlated, they are likely to be for the time or flexibility measures at the system level. The rationale for this thesis is that modernization programs implement the leading edge of manufacturing strategies, and time or flexibility are replacing quality as priorities in leading-edge domestic manufacturing.
\end{abstract}

Key Words: system-level measures, business-level outcomes, time measures, flexibility measures

\section{Introduction}

Measurement in manufacturing has become a central concern. Several studies of this problem, including those sponsored by CAM-I (Brimson, 1988) and the Boston University Manufacturing Roundtable (Vollman et al., 1988), represent significant efforts in this area in order to improve economic planning. Such terms as activity-based accounting and the hidden factory reflect some of the issues in this arena. Kaplan (1986) has written about how justification of flexible manufacturing need not be as problematic as people have thought. If the truth be known, we have just started to understand what manufacturing measurement means (Burstein, 1988). Before, few seemed to care because manufacturing did not matter or, as a function, became invisible in the corporation. There may even have been incentives not to measure. Now that has all changed.

In this article, one aspect of this issue is examined with some new evidence from a study of domestic plant modernization (Ettlie, 1988). In particular, the various measures of modernization success and failure are examined. The issue of justification per se is not raised; but the findings of our work might shed some light on future attempt to economically plan large, innovative product-process innovations in manufacturing. For one thing, there seems to be a great reluctance to include all possible costs and, especially, benefits in a financial plan for modernization. Understated, benefits such as cost of quality improvements cover unforeseen costs like manufacturer's software maintenance and additional training requirements.

Based on the best available theory and evidence from related fields, we had no reason to believe that some global measure of performance for a modernization was feasible or desirable. That does not diminish the need to measure, and multiple measures of outcomes were used in this study whenever possible. 
Financial audits of modernization projects have been difficult to obtain (Ettlie, 1987). This is changing slowly, and our data begin to document the changes in this situation. We were just as interested in explaining the variance in valid, multiple measures of modernization outcomes as the measures themseleves. But without attention to the relationship among, and meaning of, these outcomes of strategy implementation, the overall task becomes even more difficult.

The thesis of this article is quite simple. We believe that there are two meaningful levels of new production system performance measurement-the system level and the businessoutcome level. Further, since modernization programs implement the leading edge of manufacturing strategy, we expected time and flexibility to be the best predictors of business outcomes.

\section{Theory}

There are good theoretical reasons to keep various performance measures segregated, since different strategies affect outcomes differentially (Hambrick, 1983; Cameron, 1986; Skinner, 1986). In this article, the case is presented for a two-tier performance measurement scheme in the continuous audit of modernizing plants. Some or all of these measures might be relevant to steady-state monitoring of production systems, but the real issue here is the metric of change effort success-was it worth it? The degree to which any one measure can be generalized across organizations is the first guide to establishing the tiers of measurement.

The first tier is the system-based category of measures. This type of measure might be generalized across similar-type systems like flexible assembly or flexible part production, but might not work well for a new material-forming process like near-net shape. That is, some measures are probably technology specific. But generalizable metrics might include such measures as uptime (time available for production), throughput, inventory levels, cost of quality (e.g., group rates), etc.

The second tier of measures is aggregated to include business-relevant measures of performance. In the steel industry, labor hours per ton is often used; and in the automotive assembly business, labor hours per car assembled is comparable. But these measures do not capture the financial side of operations like operating costs, return on investment, cash return streams, or contribution to profit margin. The latter set of measures is often used to calculate managerial bonuses and profit shsring for the work force.

In Ettlie (1971), a study of stand-alone NC machine tools found that the two most significant correlates of utilization (percent time under computer control) were work-flow integration and managerial commitment to the new technology concept (not necessarily commitment to the particular piece of equipment and software purchased). This supports the overall assumption driving computer-integrated manufacturing (CIM) in most manufacturing establishments today, namely, that islands of automation are strategically counterproductive in manufacturing. This finding suggests that there might be a relationship within the first tier of performance measures of modernization program effectivenss. For example, measures that enhance capacity, e.g., inventory reduction or throughput reduction, might be correlated with utilization. 
Further, if one examines the philosophy of flexibility in domestic and Japanese or European production, one would not expect there to be a direct relationship between utilization and, for example, return on investment for modernization. This is because there are diminishing returns to flexibility by maximizing utilization of flexible systems that have built in restrictions in capacity, and there are trade-offs possible in many dimensions of flexibility beyond part and part-family variety.

On the other hand, in order to be consistent with the argument that time and quality are the keys to manufacturing success, uptime should be a good representative measure of system-level performance profile to predict business success. That is, time available for production maximizes the flexibility to manage a new system for trade-offs in inventory, cost of quality, and time. Whether a firm takes advantage of this uptime-as if it were a resource to be allocated-depends on other factors.

In general, the thesis is that some system-level measures are better predictors of overall business-level success with modernization, i.e., uptime, flexibility, and perhaps quality, while others are not. This is because of the preoccupation today with integrated manufacturing, which elevates the concepts of time flexibility and quality to strategic importance, in that order of dominance. If high levels of quality have not already been attained, the cause has been lost to the competition in many markets. Because of rapidly changing competitive concerns, modernization programs are likely to be on the leading edge of the implementation of manufacturing strategy, and that is why the hierarchy of relationships is predicted. The Boston University Manufacturing Roundtable recently reported that Japanese respondents currently stress flexibility, while U.S. manufacturers still rate quality as the top priority (see Roth and Miller, 1988; DeMeyer et al., 1989).

We summarize this prediction with two derived propositions:

Proposition 1. There are two tiers of meaningful performance measurement: measurement of system production (the first tier, or system level) and business outcomes for measurement (the second tier). Measures within these two tiers are more likely to be significantly correlated among themselves than between tiers.

Proposition 2. When representative measures of the first tier (system) of production are significantly correlated with those of the second tier (business), the measures are most likely to be time, flexibility, or quality related, in that order.

We test these two propositions with data collected during a study of domestic plant modernization described in the next section.

\section{Methodology}

For the purposes of clarity and simplification, modernization program outcome measures are divided into two general categories: first, those measures that are focused on the new manufacturing system itself, e.g., uptime or the time available for production; and second, program-related measures that reflect how effectively a modernization strategy has been implemented, e.g., return on investment (ROI). These measures were included from a larger 
list of nominations from engineers, managers, and previous studies (e.g., Ettlie, 1971) on pilot test interview schedules. The most popular, i.e., from plants that keep records or have data that can be extracted for use, were adopted for the final data-gathering instrument. This list is not exhaustive, nor is it necessarily the best list of measures. These measures simply represent two broad categories of numbers that can be obtained in one plant visit. Clearly, more research should be done on other possible dimensions and tiers, like innovativeness, other types of flexibility, like material changes, and changes that involve resource allocation effectiveness.

In this particular study, we randomly sampled from lists of announcements of modernization projects at domestic plants to generate cases to study over a period of three years starting in 1984. In this article, the last data collection is reported (1987) because it had the most complete set of performance measures. A total of 39 plants were visited to generate these data; most had installed either flexible, integrated manufacturing or assembly systems in the industries that typically use these technologies, such as aerospace, vehicles, appliances, etc. All regions of the country except Alaska and Hawaii were represented in the sample. The interview schedule is available from the author.

In the last panel of data collection, there was a need to replace 12 cases lost to attrition from the original set of plants. Most of these cases were lost because of a patent-challenge lawsuit that emerged between the second and third data collections. A few plants were lost because of plant closings in the oil well and drilling supply industry. Only one plant refused to continue, in this case for proprietary reasons. The final panel consisted of $19(48.7 \%)$ FMS cases broadly defined as multiple-machine, software-integrated parts-fabrication systems with integrated materials handling, and 20 non-FMS systems that were primarily assembly cells and large experimental projects like minifactories. Examples of cases not in the sample but representative of this second category are the Allen-Bradley World contactor line in Milwaukee, Wisconsin and the GE dishwasher line in Louisville, Kentucky.

All the central variables of the study were tested to see if these two broad categories of system types had any influence on measured outcomes. None exhibited the effect, with one exception: the non-FMS category, which has mostly flexible assembly systems, achieved higher labor savings percentage, as would be expected. There was also no tendency for missing data to be associated with the performance level reported. For example, ROI varied from $1 \%$ to $119 \%$ in the 14 cases reporting postaudit results.

In all cases, we asked respondents, primarily middle managers managing the modernization project, to refer to records such as production reports, quality audits, and the like. Estimates of uptime, or the time available for production, and utilization, or the percentage of time the new flexible system was actually under software control and producing parts, were based on two shifts of operation, because that is the typical base in domestic plants, with maintenance being done on third shift and weekends. Costs associated with quality, e.g., test on inspection or poor design were rarely known in these plants. Scrap and rework costs are the exception.

We did an independent validation audit on three of these measures-cycle time, uptime, and utilization-and found these measures to have rather good validity. This was accomplished by correlating system performance measures, where available, with evaluations from an industry expert and consultant on FMS. In a blind test, the independent expert assigned scores of 1 (failure), 2 (poor), 3 (average), 4 (good), and 5 (excellent) to the nine cases 
that we had available production data on from plant visits. The resulting Kendall tau rankorder correlations (used for small samples) were $\tau=.53(p<.06)$ for cycle time; $\tau=.56$ ( $p<.05$ ) for uptime; and $\tau=.45(p<.08)$ for utilization. This is a good indication of satisfactory construct validity for these types of variables using two bases of inference (Campbell and Fiske, 1959).

\section{Results}

Although measures of production performance and modernization success might be reliable and valid, they were unlikely to measure the same thing. The descriptive statistics (measures of central tendency and dispersion) of the various indicators appear in table 1 . We correlated these measures, and the results of this analysis appear in table 2.

Missing data were encountered in most measures, and the procedure for handling this situation was simply to eliminate cases on a pairwise basis. For any two measures that were correlated, cases with missing data on either measure were eliminated. In some situations, nearly all 39 cases reported, and in others, like ROI, only about a third (14) of the cases had complete data. However, since none of these measures was significantly correlated with any firm or industry characteristics, such as size, type of product, or competition environment (not shown here), we conclude that nonresponse was unrelated to these measures of intent.

Table 1. Descriptive statistics.

\begin{tabular}{lccc}
\hline \multicolumn{1}{c}{ Variable } & Mean & S.D. & $n$ \\
\hline 1. \% Cycle time achieved & & & \\
2. Uptime \% (two-shift) & 94.4 & 31.1 & 32 \\
3. Utilization \% (two-shift) & 87.3 & 11.4 & 35 \\
4. Scrap and rework \% & 72.3 & 16.8 & 34 \\
5. Throughput time reduction (\%) & 2.8 & 3.7 & 27 \\
6. Grievance filed (1-yes, 0-no) & 54.2 & 41.0 & 24 \\
7. Floor-space reduction \% & 0.33 & 0.48 & 30 \\
8. Part numbers scheduled & 38.7 & 99.2 & 25 \\
9. Part families scheduled & 562 & 2030 & 24 \\
10. Change overtime (hrs.) & 40 & 155 & 20 \\
11. \% Personnel turnover (system) & 6.25 & 22.8 & 19 \\
12. \% Absenteeism (system) & $59 \% \mathrm{~b}$ & $189 \%$ & 23 \\
13. Inventory turns (system) & 2.4 & 3.2 & 21 \\
\hline 14. \% Overbudget & 38.3 & 37.5 & 14 \\
15. Time to install (mo.) & 8 & 10.4 & 29 \\
16. Direct labor reduction (\%) & 11.7 & 10.5 & 28 \\
17. Payback period (yrs.) & 23.9 & 27.9 & 21 \\
18. ROI (\%) & 5.9 & 5.6 & 10 \\
\hline
\end{tabular}

${ }^{a}$ This percentage can exceed $100 \%$.

${ }^{\mathrm{b}}$ Median $=1 \%$ (skewed distribution). 
Table 2. Correlation matrix (sample size)

\begin{tabular}{|c|c|c|c|c|c|c|c|c|}
\hline \multicolumn{2}{|c|}{ Tier } & 1 & 2 & 3 & 4 & 5 & 6 & 7 \\
\hline 1 & $\begin{aligned} & \text { 1. } \text { \% Cycle time } \\
& \text { achieved } \\
& \text { 2. Uptime } \\
& \text { 3. Utilization } \\
& \text { 4. Scrap and rework } \\
& \text { 5. Throughput time } \\
& \text { red. } \\
& \text { 6. Grievance filed } \\
& \quad(1=\text { yes, } 0=\text { no) } \\
& \text { 7. Floor-space red. } \\
& \text { 8. Part flexibility } \\
& \text { 9. Family flexibility } \\
& \text { 10. Changeover time } \\
& \text { 11. \% Personnel } \\
& \text { turnover } \\
& \text { 12. \% Absenteeism } \\
& \text { 13. Inventory turns } \\
& \text { (sys.) }\end{aligned}$ & $\begin{array}{r}-.26(22) \\
-.17(25) \\
.01(22) \\
-.05(20) \\
.12(16) \\
.92(16)^{b}\end{array}$ & $\begin{array}{r}-.06(27) \\
-.02(25) \\
.11(24) \\
.15(20) \\
.16(18)\end{array}$ & $\begin{array}{l}.19(26) \\
.11(24) \\
.21(23) \\
.21(19) \\
.34(18)\end{array}$ & 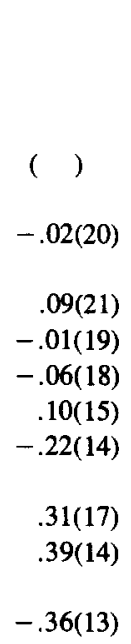 & 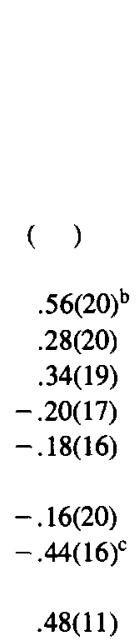 & $\begin{array}{r}(c) \\
-.01(16) \\
-.01(15) \\
.05(13) \\
.30(12)\end{array}$ & 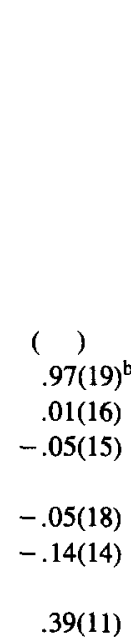 \\
\hline 2 & $\begin{array}{l}\text { 14. \% Over budget } \\
\text { 15. Time to install } \\
\text { 16. Direct labor red. } \\
\text { 17. Payback period } \\
\text { 18. ROI }\end{array}$ & $\begin{array}{r}-.08(24) \\
-.10(25) \\
.09(18) \\
-.47(9) \\
.30(13)\end{array}$ & $\begin{array}{r}.12(26) \\
-.22(27) \\
-.11(21) \\
-.13(10) \\
.62(14)^{b}\end{array}$ & $\begin{array}{r}-.03(26) \\
.01(26) \\
.26(19) \\
-.51(10) \\
.24(14)\end{array}$ & $\begin{array}{r}.13(19) \\
-.05(22) \\
.13(16) \\
-.10(8) \\
.23(11)\end{array}$ & $\begin{array}{r}-.00(23) \\
.16(25) \\
.29(18) \\
-.10(9) \\
.23(13)\end{array}$ & $\begin{array}{r}.04(14) \\
-.01(19) \\
.22(17) \\
-.30(7) \\
.21(9)\end{array}$ & $\begin{array}{r}-.08(21) \\
-.16(19) \\
.11(16) \\
-.27(8) \\
-.22(12)\end{array}$ \\
\hline
\end{tabular}

${ }^{a}$ Diagonal contains validity coefficients.

${ }^{b} p<.01$.

$c^{c} p<.05$.

\subsection{Proposition tests}

In the correlation matrix appearing in table 2 , there are 15 coefficients significant at the .05 level or better. Since there are a total of 18 measures representing two tiers, 7.7 coefficients would have been significant at the .05 level by chance. Results were sufficiently beyond the chance level to proceed with proposition testing.

Proposition 1 is a test of the two-tier division of measures for production systems. That is, significant correlation coefficients are more likely to appear for within-tier relationships than between-tier relationships. Solid lines have been added to the correlation matrix of table 2 in order to demark the two tiers of measures. Coefficients above and to the right of the solid lines are within-tier coefficients. Coefficients below and to the left of the solid lines are between-tier coefficients.

Of the 15 significant correlation coefficients, only three are for between-tier measure relationships. Among the five second-tier measures, three are significantly intercorrelated. Among the 13 first-tier measures, there are nine significant correlation coefficients. Proposition 1 is sustained by these results, and the two-tier performance measure scheme appears to be justified. 


\begin{tabular}{llllll|llll}
\hline 8 & 9 & 10 & 11 & 12 & 13 & 14 & 15 & 16 & 17 \\
\hline
\end{tabular}

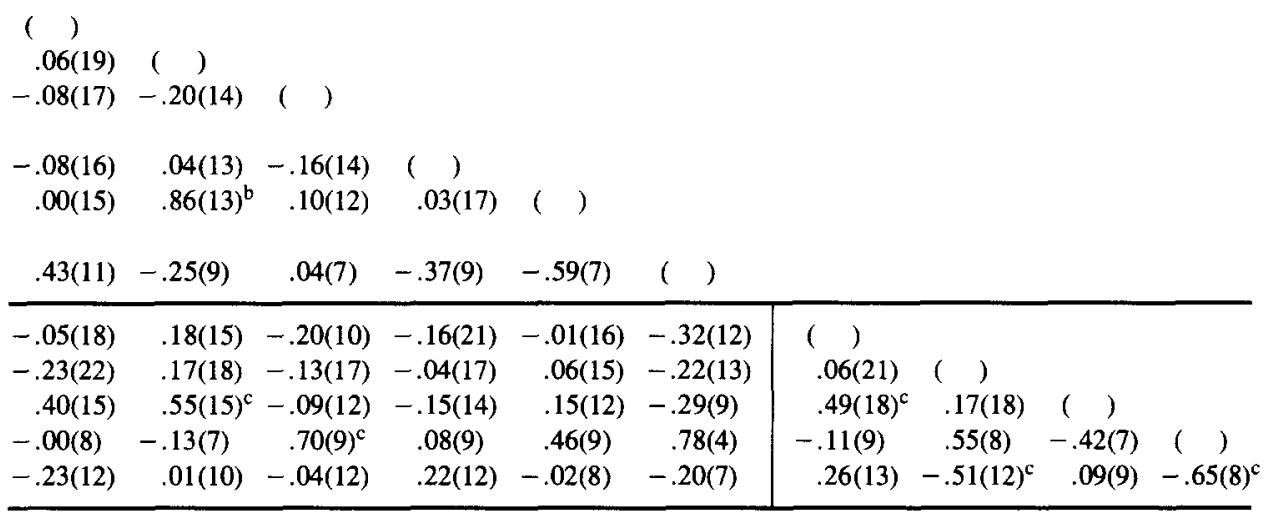

Proposition 2 states that the first-time (system) performance measures that are most likely to be related to second-tier (business) performance measures will be of three types: time, flexibility, and quality related outcomes, in that order. Examination of table 2 reveals that the three significant correlation coefficients representing between-tier relationships were

1. Uptime and return on investment $(r=.62, n=14, p<.05)$;

2. Part-family flexibility and direct labor cost reduction $(r=.55, n=15, p<.05)$; and

3. Changeover time and payback period $(r=.70, n=9, p<.05)$.

These three significant coefficients involve two of the predicted types of system-level measures (time and flexibility). All three of these relationships are in the predicted direction: uptime and ROI are directly related; part-family flexibility and direct labor cost reduction are directly related; and longer change-over-time appears to have an adverse affect on payback period, which one would expect. Short changeover time is associated with quicker payback. No quality indicators were correlated with the business outcomes that we included. In a way, uptime (time available for production) could be also considered another flexibility measure rather than a time measurement, because when it is high it allows scheduling and part-mix flexibility. In either interpretation, proposition 2 is sustained by these results. 
The failure of other first-tier measures to be correlated with second-tier measures, such as utilization or throughput time reduction (a time measure), suggests that in modernizing plants, where time and flexibility is increasing by plan (presumably as a consequence of a shift in manufacturing strategy), companies are more likely to realize their goals. It is assumed that quality measures are precursors in the modernization cycle as well as longterm outcomes, perhaps closer to a steady state or mature production condition. On average, there was a $30 \%$ improvement in quality (scrap and rework) in new systems versus existing systems in these plants. Predicting the variance in this or any other outcome was not our purpose here, but has been taken up elsewhere (Ettlie, 1988).

In general, there does seem to be a tendency for plants to seek some minimum level of technical performance success before optimization of other performance characteristics is attempted. Even when some acceptable level of new system reliability is achieved at this stage of evaluation, it appears that not all peformance measures can be simultaneously optimized.

\subsection{First-tier (system) performance measures}

As mentioned above, there were nine significant intercorrelation coefficients among firsttier performance measures. Small sample size and missing data prevent any sophisticated factor or cluster analyses of these data, but some tentative patterns do emerge and serve as suggestions for new propositions and further research.

First of all, it is comforting to find uptime and utilization to be significantly and directly related, with $r=.54$ ( $n=33, p<.05)$. In some plants these two numbers are used interchangeably because of process flowthrough characteristics. Utilization and system inventory turns were also directly related, with $r=.49(n=14, p<.05)$, which would be expected if the system were truly flexible. With the exception of scheduled maintenance, utilization and uptime are often very similar and track in parallel on production records. In some plants, the utilization percentage is computed on the basis of scheduled hours of production rather than total hours of capacity available.

Second of all, it was gratifying to see that some of the important time-based measures were also significantly intercorrelated. The percentage of target cycle time achieved (can exceed $100 \%$ ) was significantly and directly related to inventory turns within the production boundaries of the system, with $r=.86(n=7, p<.01)$, and cycle time was significantly correlated with changeover time, with $r=.92(n=16, p<.01)$.

We expected throughput time reduction to be related to system inventory turns, but the correlation coefficient did not achieve statistical significance. The direction of the relationship, however, was as predicted, with $r=.48(n=11$, n.s.). No data were available to see if throughput time, per se, was correlated significantly with turns. Plants in the sample averaged almost $50 \%$ reduction in throughput time. More surprising was the result that throughput time reduction was significantly correlated with whether or not a grievance(s) was filed on the new system, with $r=.56(n=20, p<.01)$. Consistent with this finding was the result that system inventory turns were also significantly correlated with grievances filed, with $r=.63(n=9, p<.05)$. On the other hand, throughput time reduction was inversely associated with the absenteeism rate of hourly employees working with the system, with $r=-.44(n=16, p<.05)$. 
These results, taken together, indicate that, as things change that affect the pacing of work (throughput and inventory turns), grievances are more likely. On the other hand, this throughput enhancement is likely to be positively associated with a traditional indicator of morale: absenteeism. Perhaps, when there are fewer people manning these systems, they feel the work group depends upon them more and they are less likely to miss a day. On the other hand, the increased pace of work might promote grievances from the union. Resolution and content of grievances was not tracked and might have been useful to explore this issue. It should be remembered that only about half of these plants were unionized, so these results concerning grievances ought to be kept in perspective.

The other traditional measure of morale, personnel turnover for the system group, was not significantly correlated with any other measure in either tier. One suspects this is because after extended implementation and acceleration periods for most modernization programs, there is as much "positive" as "negative" turnover among personnel associated with the project. That is, some people are promoted or become significant instruments of the corporate technology transfer mechanism and are not necessarily leaving the group because of dissatisfaction or poor performance. Stability of the technology supplier personnel group might be just as important, as well. Leftover questionnaire data that measure job satisfaction have yet to be analyzed, but might prove to be useful for predicting turnover.

Absenteeism was directly related to part-family flexibility, with $r=.86(n=13, p<.01)$. Although the number of cases is small, this does suggest that in the extreme, the high variety of work can negatively impact morale, especially during the early stages of modernization.

The only remaining first-tier relationship that was statistically significant was part flexibility and percentage reduction in floor space a a result of modernization. Overall, floorspace reduction has not emerged as a very important measure of modernization success because of the general and independent trend in domestic plants towards drastic work-inprocess inventory reductions. Whole departments in plants are being converted from inventory and storage to open space or productive floor space, so square footage is actually being created in most existing plants. However, work flow is still very much an issue in plants, so plant layout remains a key decision parameter, especially when scheduling and supply of incoming parts and materials is taken seriously.

\subsection{Second-tier (business) measures}

Like the significance of the relationship between uptime and utilization among the firsttier measures, it was gratifying to find payback period and return-on-investment for those modernization projects to be significantly correlated in the predicted direction with $r=-.65$ $(n=8, p<.05)$, even with a restricted number of cases. Firms are more sensitive about reporting second-tier or business measures, so any valid data were welcome.

Return on investment was also significantly and inversely correlated with time to install the new system, with $r=-.51(n=12, p<.05)$. During the course of the study, we noticed the emergence of time as the up-and-coming measure to be watched by general managers as well as by system managers. Based on this significant coefficient, there appears to be justification for this generalization.

Finally, there is a significant relationship between the percentage direct labor cost reduction and the percentage over budget on the project, with $r=.49(n=18, p<.05)$. This 
is a rather interesting result and subject to much conjecture. It is assumed that both forecasted labor savings and project budgets are established well in advance of actual system implementation. Therefore, this significant relationship might be the result of unexpected labor savings or unexpected cost overruns on the project. Cost overruns are usually caused by manufacturing software problems for the new systems, which suggests that the more firms or plants go after direct labor savings by modernizing, the less likely they are to stay within budget because software requirements-and perhaps general requirements-have not been well understood.

Not all of these projects with large labor savings were unsophisticated first-try efforts. Many ambitious flexible assembly and fabrication systems were included in this random sample of plants, and these projects typically realized large direct labor savings. Small FMS systems also tended to fall in this category, e.g., sheetmetal flexible systems. An ROI of $45 \%$ is typical of the latter.

Plants with ample experience to mount a significant modernization project or program are often constrained by traditional justification procedures that disallow benefit stream predictions based on cost of quality or inventory savings, and are based instead on direct labor savings. Paradoxically, many engineers and managers prefer this state of affairs. This is because the cost savings that they can ultimately realize through savings in time and headaches by modernizing, but which are not included in the financial justification process, will be a way to cover the career and capital risk of adopting a new technology for production. It is not clear how this affects adoption decisions because the review process for capital appropriations usually involves several levels in the managerial hierarchy and, often, the board of directors.

It should also be known that any relationship involving overbudget percentages will obviously be influenced by the percentage allowance given for a new technology project, which was typically $10 \%$ and in some cases higher for this sample. It might be that the reason direct labor savings are greater in plants that are over budget is because these plants allow less "buffer" in their high-risk projects. Conversely, those plants that achieve a lower direct labor savings through modernization and that are also less likely to be over budget, it seems, may also be getting returns elsewhere (indirect notwithstanding).

If there were one candidate global measure that comes closest to capturing the overall success or failure of modernization in the typical case we studied, it might be return on manufacturing research and development (R\&D). This number must capture that elusive "how much did we learn" factor in these new technology programs. It also represents or is symbolic of how far we might have come in this decade toward greater equality between product (design) R\&D and process (manufacturing) $R \& D$. This type of thinking is essential to achieving greater design-manufacturing integration as well as a realistic program of corporate technology transfer. The vast majority of our cases did not measure ROI on manufacturing $R \& D$, nor do they charge back a percentage of warranty costs attributable to poor design.

\section{Discussion}

In this article, we have begun to explore the issue of how to prudently measure the outcomes of modernization programs. Here is what we found. 
1. Production performance measures for modernization appear to fall into two general categoreis-first-tier, new system-based measures like uptime, and second-tier, businesslevel measures like ROI.

2. For modernization programs, time- and flexibility-type performance measures are the best predictors of business-level outcomes. More specifically, uptime and ROI track well together, part-family flexibility predicts achieved direct labor savings, and quicker change over time is related to favorable payback periods.

3. Several traditional productivity-based (uptime and utilization), time-based (cycle time and inventory turns), and financially based (payback period and ROI) measures intercorrelate significantly in the predicted direction within their tier for this sample of domestic plants undergoing modernization.

4. Time to install the system was significantly inversely related to ROI for the modernization project. This might be one justification for the emergence of a time-based generalmanagement system in manufacturing. The failure of quality measures and other workflow measures to emerge in this way suggests that this time-based system has not yet fully materialized in domestic manufacturing. Quality was still the number-one stated objective for the typical domestic manufacturer. Further, it is quite possible, as many have hypothesized, that quality is a prerequisite to both time and flexibility performance. Since few if any plants have valid measures of the cost of quality, one might suspect that the last battle over quality still has not been waged in domestic manufacturing. Can plants simultaneously optimize time, cost, quality, and flexibility?

We have yet to see the emergence of a global indicator of modernization success, but a candidate is suggested here: return on manufacturing $R \& D$. Perhaps the single most elusive, yet most important question that might be asked after a modernization project has ended is how much the organization's knowledge base was improved by the experience-how much did the corporation learn from the effort? As the firm changes in this way-through deliberate enhancement of this unique knowledge-the prospects for better resource allocation become better.

An important issue that has not emerged in this research, but constitutes one possible next step, involves the relationship between plant and business-unit intentions with respect to goals and strategies and actual performance. Many managers worldwide believe in the method of using simple, well-articulated objectives as a secret to success. When applied to large, complex modernizations projects that often involve new products and processes, this approach has even greater appeal. We are in the process of documenting a large flexible assembly system case history that was a follow-up project to the study reported in this article. One of the things we are struck with is the overall optimism of the technology-system supplier and plant-installing managers, engineers, and factory personnel about the ultimate outcome of this project. This project has had problems that are common to these types of cases. When compared to the "norms" represented by the central tendencies in the projects reported here, this case does not stand out as exceptional in any way-either particularly good or bad on such measures as uptime, cycle-time performance, etc. However, when one looks at labor savings that are documented and established consistently during start-up and production using this new system, the case is $200 \%$ to $300 \%$ better than the average in the large sample (the average was about $24 \%$ in table 1). The single most important stated goal of this project was to reduce labor content in these assembly tasks. One might 
question how it is possible to judge the performance of new technology without understanding the goal of the project. This is central to the manufacturing strategy perspective on this line of research.

A second and related issue is what the participants in these large projects see as the best and most valid measure of outcomes regardless of what current measurement systems monitor. We have at least one, rare case in this sample in which participants consider their unique factory-of-the-future outcome measure proprietary. If measurement itself becomes a strategic advantage, we will truly have migrated to the next generation of manufacturing management.

Third, and finally, we need to expand this line of research beyond discrete partsmanufacturing industries. This will not only enhance our measurement theory but will also add to the fund of knowledge in technology management.

\section{Acknowledgments}

Work in this area was supported by the National Science Foundation, DePaul University, The Industrial Technology Institute, and The University of Michigan. The author is responsible for the opinions in this article, and they may not reflect the official position of the funding agencies. The participation of over 90 plants and firms and over 200 respondents in various phases of this study is gratefully acknowledged. Graduate asistants on this project were Ernesto Reza, Joan Penner-Hahn, and Christopher Getner. The article was presented at the FMS III conference in Boston, MA, August 13-15, 1989.

\section{References}

Burstein, Michael C., "Life Cycle Control: Organizational Process, Reward Systems, and Performance Measurement," Proceedings of the Third Annual Cost Conference, National Association of Accountants, St. Louis, MO (September 1988).

Brimson, J.A., Activity-Based Investment Management, American Management Association, New York (1988).

Cameron, Kim S., "Effectiveness as Paradox: Conflict and Consensus in Conception of Organizational Effectiveness," Management Science, Vol. 32, No. 4, pp. 539-553 (May 1986).

Campbell, D.T. and Fiske, Donald W., "Convergent and Discriminate Validation by the Multitrait-Multimethod Matrix," Psychological Bulletin, Vol. 56, pp. 81-105 (1959).

DeMeyer, Arnoud, Nakane, Jinichiro, Miller, Jeffery G., and Ferdous, Kasra, "Flexibility: The Next Competitive Battle, The Manufacturing Futures Survey," Strategic Management Journal, Vol. 10, pp. 135-144 (1989).

Ettlie, J.E., Taking Charge of Manufacturing, Jossey-Bass Publishers, Inc., San Francisco, CA (1988).

Ettlie, John E., "Management and Robotics," in International Encyclopedia of Robotics, Vol. 2, R. Dorf (Ed.), Wiley InterScience, New York, NY, pp. 63-74 (December 1987).

Ettlie, J.E., "Technology Transfer from Innovators to Users," unpublished Masters Thesis, Northwestern University, August 1971.

Hambrick, Donald, C. " "Some Tests of the Effectiveness and Functional Attributes of Miles and Snow's Strategic Types," Academy of Management Journal, Vol. 26, No. 1, pp. 5-26 (March 1983).

Kaplan, Robert S., "Must CIM be Justified by Faith Alone," Harvard Business Review, Vol. 10, No. 2, pp. 87-95, (March-April 1986).

Roth, Aleda V. and Miller, Jeffrey G., Manufacturing Futures Factbook, Boston University, Boston, MA (1988).

Skinner, Wickham, "The Productivity Paradox," Harvard Business Review, Vol. 10, No. 5, pp. 55-59 (JulyAugust 1986).

Steers, Richard M., "Problems in the Measurement of Organizational Effectiveness," Administrative Science Quarterly, Vol. 20, No. 4, pp. 546-558 (December 1975).

Vollman, Thomas, "Changing Performance Measures," presented at the 75th Anniversary Conference: Implementing Manufacturing Strategies: Breaking the Performance Measurement Barriers, Boston, MA, October 20-21, 1988. 